\title{
NBS
}

Eechnical Mote

\section{GENERAL CHARACTERISTICS OF}

LINEAR STRAIN GAGE ACCELEROMETERS

USED IN TELEMETRY

\author{
P. S. LEDERER
}

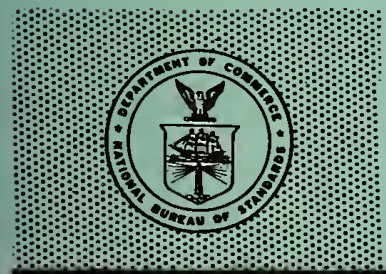

U. S. DEPARTMENT OF COMMERCE NATIONAL BUREAU OF STANDARDS 


\section{THE NATIONAL BUREAU OF STANDARDS}

\section{Functions and Activities}

The functions of the National Bureau of Standards are set forth in the Act of Congress, March 3, 1901, as amended by Congress in Public Law 619, 1950. These include the development and maintenance of the national standards of measurement and the provision of means and methods for making measurements consistent with these standards; the determination of physical constants and properties of materials; the development of methods and instruments for testing materials; devices, and structures; advisory services to government agencies on scientific and technical problems; invention and development of devices to serve special needs of the Government; and the development of standard practices, codes, and specifications. The work includes basic and applied research, development, engineering, instrumentation, testing, evaluation, calibration services, and various consultation and information services. Research projects are also performed for other government agencies when the work relates to and supplements the basic program of the Bureau or when the Bureau's unique competence is required. The scope of activities is suggested by the listing of divisions and sections on the inside of the back cover.

\section{Publications}

The results of the Bureau's research are published either in the Bureau's own series of publications or in the journals of professional and scientific societies. The Bureau itself publishes three periodicals available from the Government Printing Office: The Journal of Research, published in four separate sections, presents complete scientific and technical papers; the Technical News Bulletin presents summary and preliminary reports on work in progress; and Basic Radio Propagation Predictions provides data for determining the best frequencies to use for radio communications throughout the world. There are also five series of nonperiodical publications: Monographs, Applied Mathematics Series, Handbooks, Miscellaneous Publications, and Technical Notes.

A complete listing of the Bureau's publications can be found in National Bureau of Standards Circular 460, Publications of the National Bureau of Standards, 1901 to June 1947 ( $\$ 1.25$ ), and the Supplement to National Bureau of Standards Circular 460, July 1947 to June 1957 (\$1.50), and Miscellaneous Publication 240, July 1957 to June 1960 (Includes Titles of Papers Published in Outside Journals 1950 to 1959) (\$2.25); available from the Superintendent of Documents, Government Printing Office, Washington 25, D. C. 


\title{
NATIONAL BUREAU OF STANDARDS Eechnical Mote
}

150

JUNE 1962

\author{
GENERAL CHARACTERISTICS OF \\ LINEAR STRAIN GAGE ACCELEROMETERS \\ USED IN TELEMETRY
}

P. S. Lederer

NBS Technical Notes are designed to supplement the Bureau's regular publications program. They provide a means for making available scientific data that are of transient or limited interest. Technical Notes may be listed or referred to in the open literature. 



\section{Contents}

I. Introduction

2. Description of Strain Gage Accelerometers

3. Theory of the Ideal Seismic Plckup

3-1. Flgure of Merit, Natural Frequency, Range

4. Design Principles for Unbonded Strain Gage Accelerometers 5

4-1. Seismic Mass Determination

4-2. Electrical Sensitivity

4-3. Bridge Resistance

4-4. Design Considerations

4-4-1. Higher Gage-Factor Wire

4-4-2. Smaller Displacement

4-4-3. Higher Excitation Voltage

5. Design Principles for Bonded Strain Gage Accelerometers 15

5-1. Range, Natural Frequency and Sensitivity 15

5-2. Electrical Sensitivity

5-3. Bridge Resistance

5-4. Design Considerations

5-4-1. Semiconductor Strain Gages

5-4-2. Low Modulus Beam Material

5-4-3. Higher Excitation Voltage

19

19

19

22

22

22

5-5. Characteristics of Bonded Strain Gages

6. Frequency Response of Strain Gage Accelerometers

23

24

28

7. Performance Characteristics

7-1. Accuracy and Fldelity

7-2. Repeatability

7-2-1. Short Term Repeatability

28

30

30

7-2-2. Long Term Repeatability

31

7-3. Linearity

7-4. Hysteresis

31

32

7-5. Resolution

7-6. Response to Transverse Excitation

7-6-1. Transverse Response to Steady State Accelerations

7-6-2. Transverse Response to Vibrational Accelerations

7-7. Temperature Effects

7-7-1. Slowly Changing Ambient Temperatures

7-7-1-1. Zero Shift

7-7-1-2. Sensitivity Change

36

7-7-1-3. Effects on Dymamic Characteristics

7-7-2. Thermal Transients

7-8. Tolerance to Envirormental Extremes

7-8-1. Steady Acceleration Overload

7-8-2. Vibration and Shock Along the Sensitive Axis

39

40

41

41

7-8-3. Acoustic (Airborne) Noise

42

7-8-4. Extremes of Ambient Temperatures

43

43

7-8-4-1. Effects on Unbonded Strain Gages

43

7-8-4-2. Effects on Bonded Strain Gages

44

7-8-4-3. Effects on Cantilever Beam (Spring) Materials

46

7-8-4-4. Damping

7-8-5. Ambient Pressure Variations

7-8-6. Effects of Nuclear Radiation

46

47

48

7-8-7. Other Environmental Conditions

48 


\begin{abstract}
This paper presents a summary of pertinent information, theoretical and experimental, on the design characteristics, performance capabilities and limitations of strain gage accelerometers used in telemetry. Properties and characteristics of unbonded and bonded types of strain gage accelerometers are discussed.
\end{abstract}


GENERAI CHARACTERISTICS OF LINEAR STRAIN GAGE

ACCELEROMETERS USED IN TELEMETRY

P. S. LEDERER

\section{INTRODUCTION}

Linear acceleration is one of the important parameters measured in the flight testing of airplanes, missiles and space vehicles, and transmitted to the ground receiving station by means of telemetry.

Two general types of instruments are used to measure accelerations. Vibration and shock pickups are seismic instruments which, while generally not having any response to steady acceleration, are capable of sensing accelerations over very wide amplitude and frequency ranges. They are used primarily for the measurement of vibrations and shock due to environmental conditions.

Spring-mass accelerometers, which respond to steady accelerations as well as changing or transient accelerations, are generally used when measurements are to be made of steady accelerations or a faithful record of the total acceleration-time history is required. These instmuments are used for attitude and flight path determination, as well as flight control. They may also be used to measure vibrations and shock, but within narrower amplitude and frequency ranges than vibration pickups. The basic element of a spring mass accelerometer is a seismic mass suspended on a spring which is attached to the case of the instrument. The motion of the case can be indicated by the relative motion of the seismic mass with respect to the case.

This paper describes one class of spring-mass accelerometers, those using resistance strain gages to sense the relative motion of the seismic 
mass. There are two types: unbonded strain gage accelerometers and bonded strain gage accelerometers.

While an effort was made to cover readily available literature on the subject, no exhaustive literature survey was attempted. The experimental results cited are derived largely from tests performed on strain gage accelerometers in the Mechanical Instruments Section of the National Bureau of Standards as part of a program dealing with the development of improved evaluation techniques for telemetering transducers.

\section{DESCRIPIION OF STRAIN GAGE ACCELEROMETERS}

In the case of an unbonded strain gage accelerometer, the strain wires supply almost the entire spring force in the spring mass system and auxiliary springs serve only to restrict the mass to motion along the sensitive axis; the resistance of the strain wires is a function of the displacement of the mass with respect to the case. Under certain conditions, this is proportional to the acceleration to which the case is subjected. Therefore, the output of the strain gage is a measure of the applied acceleration.

A bonded strain gage accelerometer generally consists of a mass attached to the end of one or more cantilever beams mounted in the instrument case. Strain gages are attached to the surface of the beam so as to measure the deflection of the mass in terms of the strain along the beam surface. As above, under certain conditions, the deflection of the mass is proportional to the applied acceleration, and therefore, the output of the strain gages is a measure of the acceleration. In both types, viscous damping is provided to increase the frequency range over which accurate measurements may be taken and to damp out transient oscillations due to high frequency excitation. 


\section{THEORY OF THE IDEAL SEISMIC PICKUP}

The relationship between $\underline{x}$, the relative motion between the seismic mass and the case, and the motion of the case $\underline{y}$, for an ideal seismic pickup with lumped constants is:

$$
\ddot{x}+4 \pi n f_{n} \dot{x}+4 \pi^{2} f_{n}^{2} x=-\ddot{y}
$$

where

$$
\mathrm{y}=\text { displacement of case, inches }
$$

$x=$ relative displacement between mass and case, inches

$\mathrm{n}=\frac{\mathrm{C}}{\mathrm{C}_{\mathrm{c}}}$ the damping ratio

$f_{n}=\frac{1}{2 \pi} \sqrt{\frac{k}{m}}$ the natural frequency of the pickup cycles per second.

$m=$ seismic mass, pounds second squared per inch.

$\mathrm{k}=$ spring constant, pounds per inch.

$C=$ equivalent viscous damping constant pounds per inch per second.

$C_{c}=2 \sqrt{\mathrm{km}}$, critical damping constant, pounds per inch per second. (See Reference 1, 11.)

For sinusoidal motions of the case at frequency $f$ and peak displacement $\mathrm{y}_{0}$, the instantaneous case displacement $\underline{\mathrm{y}}$ is given by

$$
y=y_{0} \sin 2 \pi f t
$$

The steady state solution of equation (1) for the relative displacement between mass and case becomes

$$
x=y_{0} \frac{\frac{f^{2}}{f_{n}^{2}}}{\sqrt{\left(1-\frac{f^{2}}{f_{n^{2}}}\right)^{2}+\left(2 n \frac{f^{2}}{f_{n^{2}}}\right)^{2}}} \sin \left[2 \pi f t-\tan ^{-1}\left(\frac{2 n \frac{f}{f_{n}}}{1-\frac{f^{2}}{f_{n^{2}}}}\right)\right]
$$


If, $\frac{f}{f_{n}}<0.6$ and $n \approx 0.65$, (most accelerometers are designed to have these characteristics), then

$$
\mathrm{x} \approx \mathrm{y}_{0} \mathrm{f}_{\mathrm{n}^{2}} \sin 2 \pi \mathrm{ft}
$$

The acceleration of the case is equal to

$$
\ddot{y}=-y_{0} 4 \pi^{2} f_{n} 2 \sin 2 \pi f t
$$

therefore, substituting in (4)

$$
\left.x \approx-\frac{y}{4 \pi^{2} f_{n^{2}}} \quad \text { (See Reference } 1\right)
$$

As long as the accelerometer is used at frequencies below $60 \%$ of its natural frequency and is damped near $65 \%$ of critical, the relative displacement between the seismic mass and the case is equal to the acceleration amplitude divided by the square of the natural frequency to a good approximation. Since the peak acceleration amplitude is generally expressed in "G" units (multiples of the acceleration due to gravity, 386 inches $/ \mathrm{sec}^{2}$ equation (6) can be written as

$$
\begin{aligned}
& x \text { peak }=9.77 \frac{G}{f_{n}^{2}} \\
& G=\text { peak acceleration, G-units }
\end{aligned}
$$

This is the basic relationship used in the design of strain gage accelerometers.

3-1. Flgure of Merit, Natural Frequency, Range.

Although there are some applications, where it is necessary to sense low frequency accelerations in the presence of high frequency vibrations, and where an accelerometer with a low natural frequency may be used, which would then be comparatively insensitive to the high frequency vibrations, for a general purpose accelerometer of given range it is 
desirable to have as high a natural frequency as possible with a given range of acceleration, output, etc. The higher the natural frequency, the wider the frequency range of sinusoidal accelerations sensed and the more faithful the measurement of nonsinusoidal accelerations consisting of many frequency components.

Thus the ratio of the natural frequency to the range of the accelerometer constitutes a figure of merit, which, all other things being equal, it is desirable to have as large as possible. Equation (7) shows that a high figure of merit requires a low sensitivity, in terms of displacement per unit acceleration, so that the practical limitation or figure of merit is the effective resolution of the accelerometer. Moreover, it is seen from this equation that the figure of merit is better expressed in terms of the square of the natural frequency.

The figure of merit, $M$, of an accelerometer represents an important design criterion and is given by

$$
M=\frac{f_{n}{ }^{2}}{G}=\frac{9.77}{x \text { peak }}
$$

\section{DESIGN PRINCIPLES FOR UNBONDED STRAIN GAGE ACCELEROMETERS}

\section{4-1. Seismic Mass Determination.}

In the case of unbonded strain gage accelerometers, most of the spring force is supplied by the strain wires, themselves. Cantilever flexure plates, which contribute a very small amount of spring force, are used to restrict the mass to rectilinear motion. In the design of such an accelerometer, the incremental value of strain produced in the wires when the mass responds to the full scale value of acceleration is 
generally limited to the maximum of 0.0015 inch per inch of gage length. During assembly, sufficient initial tension is applied to the strain sensitive resistance wires to keep them under some residual tension when the mass is in either extreme position. Travel of the mass is limited mechanically to protect the wires from overloads. 2, See Figure 1.

It is desirable to have the vibrating mass in the accelerometer as small as possible to minimize the volume and weight of the instrument and to require that as little energy as possible need be taken from the system whose acceleration or vibration is to be measured.

The basic design equation for unbonded strain gage accelerometers describes the seismic mass in terms of the other design parameters. The equation is derived by considering the mass-spring system to have been set into free sinusoidal oscillation at its natural frequency by an initial displacement (damping is neglected). During each oscillation, the kinetic energy of the moving mass is transferred into potential energy of spring displacement and recovered again. Since no loss of energy occurs due to damping, the maximum kinetic energy of the mass during each cycle must equal the maximum potential energy stored in the spring during this cycle. The spring force contributed by the flexure plates is usually quite small compared to that due to the strain wires and is therefore neglected in the following derivation. The maximum kinetic energy of the mass is given by:

$$
T_{\max }=\frac{1}{2} m v_{\max }^{2}
$$

since the motion is sinusoidal, the maximum velocity is

$$
V_{\max }=2 \pi f_{n} x_{\max }
$$

therefore 


$$
T_{\max }=\frac{1}{2} m \quad 4 \pi^{2} f_{n}^{2} x_{\max }^{2}
$$

and from this, in consistent units

$$
\mathrm{m}=\mathrm{T}_{\max } \frac{386}{2 \pi^{2} f_{n}^{2} x^{2} \text { max }}
$$

Substituting equation (7) in equation (12) yields

$$
\begin{aligned}
& \mathrm{m}=\mathrm{T}_{\max } \frac{386 f_{n}{ }^{2}}{2 \pi^{2}(9.77)^{2} G^{2}} \\
& \mathrm{~m}=.208 \mathrm{Tmax} \frac{f_{n^{2}}}{G^{2}}
\end{aligned}
$$

The maximum potential energy stored in the strain wire in terms of the spring constant $k$ and the design strain $\varepsilon$ and the total length of strain wire $\mathrm{S}$ is given by:

$$
\mathrm{P}_{\max }=\frac{1}{2} \mathrm{Sk} \boldsymbol{\varepsilon}^{2}
$$

The spring constant $\mathrm{k}$ is a function of the elastic modulus of the strain wire $Y$ and its cross-sectional area $A$, that is,

$$
k=Y A
$$

or in terms of the wire diameter

$$
k=\frac{1}{4} \pi Y^{2}
$$

therefore

$$
P_{\max }=\frac{1}{8} \pi S \mathrm{SY}^{2} \boldsymbol{\varepsilon}^{2}
$$

since $\mathrm{P}_{\max }=\mathrm{T}_{\max }$, substituting (16) in (13) results in

$$
m=8.07 \times 10^{-2} \varepsilon^{2} \mathrm{SYd}^{2} \frac{f_{n}^{2}}{G^{2}}
$$

where

$$
\begin{aligned}
& \mathrm{m}=\text { mass, } 1 \mathrm{~b} . \\
& \boldsymbol{\varepsilon}=\text { design strain, inches/inch } \\
& \mathrm{S}=\text { total length of strain wire, inches }
\end{aligned}
$$




$$
\begin{aligned}
Y & =\text { modulus of elasticity of strain wire, } l \mathrm{~b} / \mathrm{in}^{2} \\
\mathrm{~d} & =\text { diameter of strain wire, inches } \\
f_{n} & =\text { natural frequency, cps } \\
G & =\text { maximum range of accelerometer, from zero, in "G" units }
\end{aligned}
$$

(See references 2 and 11).

In the case of unbonded strain gage accelerometers with the maximum design strain of 0.0015 inches per inch, equation (16) becomes

$$
m=18.2 \times 10^{-8} \mathrm{SYd}^{2} \quad \frac{f_{n^{2}}}{G^{2}}
$$

This is the second important design criterion. The actual design must represent a compromise since, as pointed out above, $\mathrm{m}$ is desired to be small, but the figure of merit, and therefore the term $\frac{f_{n^{2}}}{G^{2}}$ to be large.

\section{4-2. Electrical Sensitivity.}

The electrical output of a linear strain gage accelerometer is based on the following considerations. The electrical pickoff generally consists of a bridge with four active arms. The output of such a bridge is

$$
\begin{aligned}
V= & \frac{\Delta}{R} \frac{R}{R} \\
\frac{\Delta R}{R}= & \text { fractional change in resistance of each of the four } \\
& \text { active arms of bridge. }
\end{aligned}
$$

The gage factor of the strain wire, $\mathrm{K}_{\mathrm{S}}$ given by

$$
\mathrm{K}_{\mathrm{S}}=\frac{\Delta R}{\mathrm{R}} / \mathrm{E}
$$

which, on substituting in (18), becomes

where

$$
\mathrm{V}=\mathrm{E} \mathrm{K}_{\mathrm{S}} \boldsymbol{E}
$$

$$
E \text { = bridge excitation voltage, volts }
$$




$$
\begin{aligned}
\mathrm{K}_{\mathbf{S}} & =\text { gage factor of strain wire } \\
\mathbf{E} & =\text { design strain, inches/inch }
\end{aligned}
$$

The sensitivity, $Q$, of the accelerometer is therefore

$$
Q=\frac{V}{E}=1000 K_{S} E
$$

where

$Q=$ sensitivity, millivolts per volt excitation for full range acceleration.

\section{4-3. Bridge Resistance.}

The resistance of a bridge with four equal active arms is equal to the resistance of one of the arms. It can be computed from

$$
R=2.08 \times 10^{-8} \frac{\rho S}{d^{2}} \text { ohms }
$$

$S=$ total length of wire in bridge, inches

$\mathrm{d}=$ diameter of wire, inches

$\rho=$ resistivity, ohms per circular milfoot

Commonly used bridge resistances are 120 ohms, 180 ohms, 350 ohms and about 3000 ohms.

4-4. Design Considerations.

If one considers an unbonded strain gage accelerometer with a gage length of one inch (a common value for a commercial instrument) and if the mass is furthermore considered to act directly on the strain wires and strain them to the full scale value of \pm 0.0015 inches the resulting figure of merit for this instmment would be $M=\frac{f_{n}^{2}}{G}=6530$.

The most commonly used materials for the strain wires in such accelerometers are "Constantan" ("advance"), an alloy of copper and nickel with a gage factor of about 2.0, and "alloy 479", an alloy of platinum and tungsten, with gage factor near $4.0 .^{2}$ The sensitivity of 
the accelerometers (Equation 22) would then be about $3.0 \mathrm{MV} / \mathrm{V}$ and about 6.0 MV/v, respectively, for full range output.

Table 1 contains the characteristics of a number of commercial unbonded strain gage accelerometers obtained from the manufacturers literature. From this it can be seen that sensitivities fall into two ranges: 1.89 to $2.33 \mathrm{MV} / \mathrm{v}$, and 3.89 to $4.58 \mathrm{MV} / \mathrm{v}$, corresponding roughly to the computed sensitivities. It is also apparent that the computed figures of merit in the table are near that shown above $\left(\frac{f_{n} 2}{G}=6530\right)$ for a postulated strain of 0.0015 only in three cases. It appears then that in these cases the seismic mass acts directly on the strain wires, and in straining them 0.0015 inches/inch, actually moves .0015 inch (for a one inch gage length). In the other cases, leverage exists between the mass and the strain wires so that, for $M<6530$ the mass moves a greater distance than that due only to the stretching of the strain wires; conversely for $M>6530$, the mass moves a shorter distance.

The design requirements for the majority of accelerometers, that is, high natural frequency and high sensitivity, are contradictory. The large displacement of the seismic mass required to generate a large value of strain, and thereby a high output voltage, will also reduce the natural frequency. However there are several means of, at least partially, circumventing the difficulty.

\section{4-4-1. Higher Gage-Factor Wire.}

The use of strain wire of higher gage factor will result in higher sensitivity and therefore higher output voltage at the same electrical excitation and strain. Currently, "alloy 479" with a gage factor of 
about 4.0 represents the limit in reproducible stable, temperature insensitive strain gage wire materials. 8 (Commonly used constantan has a gage factor of about 2.0). Recently developed semiconductor strain gages of very high gage factors will be covered in the section on "bonded strain gage accelerometers".

4-4-2. Smaller Displacement.

Smaller displacement of the seismic mass can result in the same strain in the wires if leverage is used. This requires a larger mass (see equation 18) and limitations here are imposed by the mass which is desired to be small to minimize instrument welght and therefore energy taken from the system whose acceleration is to be measured. Space and stiffness requirements Iimit the leverage to a factor of about five. 4-4-3. Higher Excitation Voltage.

The output voltage can be raised by increasing the excitation voltage. The limitation here is imposed by the allowable heat dissipation of the strain wires. With insufficient dissipation, the temperature of the strain wires may rise until the wires sag (causing nonlinear output) or actually melt. The allowable heat dissipation of the wires depends on the heat transfer characteristics of the medium surrounding the wires. Table 1 indicates allowable excitation voltages up to 12 volts for a number of instruments known to be filled with damping oil which is a good heat conductor. The power dissipated in these instruments may therefore reach 0.4 watts. The table also shows the allowable excitation for another group of accelerometers to be only 5 volts (power dissipated: 0.07 watts); in these instmments, the strain gages are in air, 
which is a poor heat conductor.

It does not appear practical to get higher output voltages by just increasing the maximum strain: for one thing, the natural frequency would be decreased by the required increased deflection; for another, the present design strains may approach the proportional limit for the wires. This is true because the design strain referred to throughout this section, 0.0015 inches/inch is really an incremental strain. The mass of the standard bi-directional accelerometer, capable of movement in two directions, will thereby reduce the strain in one part of the strain gage bridge as it increases the strain in the other. In order to avoid wire sag (and output nonlinearity) when the strain is reduced, the wires must be under initial tension. Additional tension must be added to allow for wire expansion caused by the current through it and that due to differential expansion of the components in the accelerometer caused by environmental temperature changes. When all these are taken into account, the final maximum strain in the wire may well reach three times the incremental design strain.

A relatively new design approach 6 shown schematically in Fig. 2 seems to get around this problem. It is the "zero length" strain gage which derives its name from the fact that the points at which the strain sensitive wire are attached to the fixed and movable members are longitudinally superimposed by mounting the wire in a V-shaped configuration. One end of the wire is attached to a fixed member of the instrument structure, the other to the moving one (seismic mass). The midpoint of the wire is connected to the instrument structure through a sliding con- 
tact at the end of a long spring with a low spring rate so that the tension it exerts remains essentially constant for small changes in its length even with extension of the wire due to heating.

The sum of the tensions in the two sections of the wire is constant and equal to the tension exerted by the spring. When the movable member is displaced from its normal position an amount b, the point of attachment of the spring will move along the wire by an amount $\frac{b}{2}$. This will result in an increase in the length of one half of the wire by an amount $\frac{b}{2}$ and a decrease in length of $\frac{b}{2}$ of the other half of the wire. Since the strain wire is kept under relatively constant tension by the spring, despite the movement, a change in length results in a corresponding change in resistance of each section of the wire. If the two sections of the wire are connected as part of a bridge circuit, the resultant resistance changes produce an output proportional to the displacement of the movable member. Most "zero length" strain gage devices employ two such configurations in a four arm bridge. This design produces relative immunity from overloading and permits higher excitation voltages since wire sag with heating is counteracted by the spring.

Finally, one accelerometer in the table shows a very high figure of merit as well as high sensitivity. This instrument employs "gas damping". A piston or diaphragm attached to the seismic mass serves to close a small chamber equipped with a restriction. Movement of the seismic mass moves the piston or diaphragm and thereby forces gas to flow through the restriction which dissipates the energy of motion and furnishes damping to the system. In addition to gas flow, there is also 
compression and expansion of the gas in the chamber. The pneumatic spring created and the existing spring of the strain wires in conjunction with the seismic mass will determine the dynamic characteristics of the accelerometer. An understanding may be gained of the properties of such a system ${ }^{16}$ by considering the two extreme cases. If no restriction exists to the flow of gas to and from the chamber there will be no damping. Movement of the seismic mass will not change the pressure of the gas in the chamber. This eliminates pneumatic spring action. The accelerometer would behave somewhat like an undamped single degree of freedom system with a relatively low natural frequency.

If the restriction is such that no gas can flow through it, the pressure of the gas in the chamber will change with seismic mass motion and resist the motion. The net effect is a stiffer spring which results in a much higher natural frequency than above. Since practically no energy is dissipated (no flow) the system again appears undamped.

It seems feasible then by proper choice of the parameters of the restriction to achieve a system with a relatively wide and flat frequency response. Furthermore since damping depends on the viscosity of the gas and since the viscosity of a gas is much less temperature dependent than that of a liquid, the frequency response of a gas damped instrument is less effected by changes in ambient temperature.

Such a system is, however, nonlinear. As the amplitude of motion increases, at constant frequency, the quantity of gas which can flow through the restriction does not increase proportionately and the pneumatic spring becomes stiffer. This results in a proportionately decreased electrical output. 
The values of natural frequency listed for these accelerometers can be computed for the basic system ${ }^{11}$ without gas damping. This was done so as to arrive at a figure of merit which permits comparison with the other accelerometers. The values obtained indicate that apparently leverage is also employed between the seismic mass and the strain wires to reduce the required displacement of the mass by a factor of about four.

5. DESIGN PRINCIPLES FOR BONDED STRAIN GAGE ACCELEROMETERS 5-1. Range, Natural Frequency and Sensitivity.

Bonded strain gage accelerometers basically consist of a weight mounted on a uniform cantilever beam leaf spring with the strain gages bonded to the spring. Practical instruments frequently use two cantilever beams joined by a common weight and mounted in such a manner that strains produced by transverse accelerations acting along the axis of the beams are cancelled out. In the design of a bonded strain gage accelerometer, the value of strain acting on the strain gage for the full scale value of acceleration is generally limited to about 0.001 inches/ inch (1000 micro-inches per inch). This is done so as not to overstress the cantilever beam and also to prevent fatigue failure of the strain gage. (The latter may occur at the junction of gage wires and lead wires at high strain levels).

The theory of simple structures applied to an ideal (weightless) cantilever beam with a weight $W$ at its free end shows that the maximum unit fibre stress at a distance $Z$ from the fixed end of the beam due to gravity is

$$
\boldsymbol{\sigma}=\frac{W(L-Z) h}{2 I}
$$


where $W(L-Z)$ is the bending moment at the distances $Z$ from the fixed end of the beam

$$
\begin{aligned}
& \boldsymbol{\sigma}=\text { unit fibre stress, pounds per square inch } \\
& h=\text { height of beam, inches } \\
& \mathrm{Z}=\text { distance from fixed end of beam, inches } \\
& I=\text { moment of inertia of beam, inches }{ }^{4} \\
& W=\text { weight, pounds } \\
& L=\text { length of beam, inches }
\end{aligned}
$$

If an acceleration of "G" times the force of gravity acts on the weight $W$, the resulting fibre stress at $Z$ will be

$$
\sigma=\frac{W G(L-Z) h}{2 I}
$$

If this fibre stress is within the proportional limit of the beam's material, the corresponding strain in the outermost fibres will be

$$
E=\frac{\sigma}{Y}=\frac{W G(I-Z) h}{2 I Y}
$$

where $\quad Y=$ modulus of elasticity of beam material

$\boldsymbol{E}=$ strain, inches per inch at $\mathrm{Z}$

The deflection of the free end of the beam under the action of the force of gravity is

$$
u=\frac{W L^{3}}{3 I Y}
$$

where $u=$ deflection of end of beam, inches:

The natural frequency of a spring mass system in the gravitational field can be expressed by

$$
f_{n}=\frac{1}{2 \pi} \sqrt{\frac{a}{u}}
$$



second.

Therefore, the natural frequency of this cantilever beam system can be expressed as

$$
f_{n}=\frac{1}{2 \pi} \sqrt{\frac{3 I Y a}{W L^{3}}}
$$

Squaring and rearranging the above relation, the following equation is obtained

$$
\frac{T Y}{W}=\frac{4 \pi^{2} T^{3} f_{n}^{2}}{3 a}
$$

From equation (26) it follows that

$$
\frac{T Y}{\mathrm{~W}}=\frac{G(\mathrm{~L}-\mathrm{Z}) \mathrm{h}}{2 \boldsymbol{E}}
$$

at one "G" this becomes

$$
\frac{I Y}{W}=\frac{(L-Z) h}{2 \varepsilon}
$$

Equating the equations (30) and (32), the following is obtained:

$$
\varepsilon=\frac{3 a}{8 \pi^{2}} \quad \frac{(L-Z) h}{L^{3} f_{n}^{2}} \quad \text { (See Reference 10) }
$$

This describes the fibre strain in inches per inch for this cantilever beam accelerometer due to the force of gravity (or for one "G") in terms of beam dimensions and natural frequency. The fibre strain will be directly proportional to the acceleration in "G" units.

The relations developed above apply equally well to systems with two cantilever beams joined by a common weight. This is true since one cantilever beam of width $b$ is equivalent in all respects to two cantilevers (joined) of width $\frac{b}{2}$, with all other dimensions unchanged. 
By rearranging the above relation and substituting some numerical values, a figure of merit can be obtained for a bonded strain gage accelerometer just as was done for unbonded strain gage accelerometers

$$
M=\frac{f_{n}^{2}}{G}=\frac{3 a(L-Z) h}{8 \pi^{2} L^{3} \xi_{\max }}
$$

where $\quad \varepsilon_{\max }=$ strain due to full scale acceleration in "G" units.

In most bonded strain gage accelerometers, the strain gage is mounted very close to the fixed end of the beam. This makes the distance Z (strain gage centered on Z) small compared to I. Therefore,

$$
\frac{I-Z}{I^{3}} \approx \frac{I}{L^{3}}=\frac{I}{L^{2}}
$$

The maximum value of full scale fibre strain is generally taken to be 0.001 inches/inch. On substituting these values, the figure of merit of the bonded strain gage accelerometer becomes

$$
M=\frac{f_{n}^{2}}{G}=1.47 \times 10^{4} \frac{\mathrm{h}}{\mathrm{L}^{2}}
$$

The weight required at the end of the beam is given by

$$
W=\frac{3 a I Y}{4 \pi^{2} I^{3} f_{n}^{2}}
$$

For a rectangular cross section beam of width $b$, height $h$ the weight becomes

$$
w=\frac{a Y b n^{3}}{16 \pi^{2} I^{3} f_{n}^{2}}
$$

For such a rectangular cross section beam, the fiber strain is

$$
\varepsilon=\frac{6 W G(I-Z)}{Y b h^{2}}
$$

Thus the strain produced (everything else remaining constant) is inver- 
sely proportional to the square of the boam helght $b$. Since the figure of merit is alrectly proportional to beam height $h$, the design of a bonded strain gage accelerometer must be a compromise between a high figure of merit and high sensitivity.

5-2. Electrical Sensitivity.

The sensitivity for a bonded strain gage accelerometer with a bridge with four equal active arms is also given in millivolts per volt excitation for full range output by equation (2l), 1.e., Q $=1000 \mathrm{~K}_{\mathrm{S}} \mathbf{E}$ 5-3. Bridge Resistance.

The resistance of a bridge with equal active arms is equal to the resistance of one of the arms. Commercial bonded strain gages can be obtained in a variety of resistance values. The most commonly used ones are: 120 ohms, 350 ohms, 500 ohms and 1000 ohms.

5-4. Design Considerations.

The two most commonly used materials for wires in a bonded strain gage are "constantan" (as used in unbonded strain gage instruments) with a gage factor of about 2.0, and "iso-elastic", an alloy of iron, nickel, and chromium, with a gage factor of about $3.30^{3}$ Although "iso-elastic" has a higher gage factor than "constantan" and has an improved fatigue life, it has a much higher temperature coefficient of resistance. 8

Instead of wire, bonded strain gages are often constructed of metallic foils or films. Commonly used materials for these are: "constantan", and "nichrome V", an alloy of nickel and chromium, with a gage factor of about 2.4. Foll gages show a slightly higher gage factor than wire gages made of the same material and dissipate heat better, 
thereby permitting operation with higher excitation voltages. Although most of these gages will measure strains up to 0.005 inches/inch satisfactorily, fatigue life is greatly improved by limiting the maximum strain to 0.002 inches/inch and frequently to 0.001 inches/inch.

At the design strain of 0.001 inches/inch, the sensitivities of accelerometers with strain gages made of the above materials would be expected to range from about $2.0 \mathrm{MV} / \mathrm{V}$ to $3.3 \mathrm{MV} / \mathrm{V}$ for full range output.

Bonded strain gages are available which utilize the piezo resistive properties of semiconductor materials, like germanium and silicon. These semiconductor strain gages have very high gage factors, ranging from about 70 to 250. However, the gage factor is quite temperature dependent, so that if an instrument is to operate over an appreciable temperature range, some form of compensation must be employed. The maximum strain level for these semiconductor gages is about 0.003 inches/ inch. Table $2 a$ lists the characteristics as obtained from the manufacturers literature of a number of commercial bonded strain gage accelerometers.

For the wire or foil gage type, sensitivities correspond to those of the unbonded strain gage accelerometers. Figures of merit are much lower. As an example, an unbonded strain gage accelerometer with a range of \pm 2 G's has a natural frequency of $100 \mathrm{cps}$; its bonded counterpart has a natural frequency of $25 \mathrm{cps}$.

This difference in figure of merit is easily understandable when one considers that the figure of merit $\left(\frac{f^{2}}{G}\right)$ is the reciprocal of the full scale displacement of the seismic weight. Whereas, in the unbonded 
strain gage accelerometer, the strain in the wires is produced directly by the displacement of the seismic weight, in the bonded strain gage instrument this strain is produced through the medium of a cantilever beam. A considerable deflection of the free end of the beam (displacement of the seismic weight) is necessary to produce the required strain in the fibers of the beam where strain gages are attached. It can be shown that the ratio of the deflection of the end of the beam to the strain produced in outermost fibers of the beam at the fixed end is

$$
\frac{u}{\varepsilon}=\frac{2 L}{3 h}
$$

For the bonded strain gage accelerometer described above, this ratio was computed to be 34. For the same amount of strain produced by acceleration then, the weight in the "bonded" accelerometer has to be displaced about 34 times as far as that in the "unbonded" instrument assuming unity gage length. This should result in a natural frequency for the "bonded" instrument roughly one sixth of that of the "unbonded" one. Manufacturing tolerances may account for discrepancies between measured and computed values.

In Table $2 \mathrm{~b}$, the characteristics of the two accelerometers using semiconductor strain gages show the expected high sensitivity combined with the high figure of merit normally associated with unbonded strain gage accelerometers. While the manufacturer of these two instmuments markets semiconductor strain gages for bonded use, the sensitivity and figure of merit listed do not seem consistent with the design characteristics imposed by the use of the seismic mass mounted on a beam to which the strain gages are bonded. 
5-4-1. Semiconductor Strain Gages.

One possible way of achieving high sensitivity with a relatively high natural frequency is by the use of the new semiconductor strain gages in place of wire wound strain gages. 5-4-2. Low Modulus Beam Material.

Another one is by the use of a beam material with a low modulus of elasticity. Copper alloys like phosphor, bronze or beryllium copper possess a modulus of elasticity of half that of steel. The improvement is not spectacular. However halving the modulus and with unchanged deflection of the seismic mass, the maximum strain, and therefore the sensitivity, increase by about $25 \%$. 5-4-3. Higher Excitation Voltage.

The output voltage can be raised by increasing the excitation voltage. As before the limiting factor is allowable heat dissipation, but bonded strain gages being mounted on a heat sink (the beam) can dissipate more power. Allowable levels (from the table) are from 0.53 to 0.75 watts, more than for unbonded strain gages.

Very often, the weight of an "unbonded" accelerometer is considerably less than that of its "bonded" counterpart (due to smaller mass required by the former to produce the same strain, and therefore output, for the same value of acceleration). This may be a very important consideration where it is required to measure the motion of some object by means of an accelerometer. If this object is itself the mass of a seismic system, the natural frequency of that system will be

$$
\frac{1}{2 \pi} \sqrt{\frac{k}{m}} \text {. }
$$


If, now, an accelerometer of mass $M_{e}$ were mounted on the object and if $\mathrm{M}_{e}$ were, say $0.2 \mathrm{~m}$, the natural frequency of the seismic system would be reduced to

$$
f_{t}=\sqrt{\frac{k}{m+0.2 m}}=.91 f_{n}
$$

5-5. Characteristics of Bonded Strain Gages.

Despite the fact that bonded strain gages have been used for a number of years, much of the information about their characteristics is inconsistent and unreliable. This is not due to any lack of effort or skill on the part of investigators, but rather due to the fact that strain gages, even of the same type, differ in characteristics when mounted. This, in turn, is due to such factors as composition of the mounting surface, preparation of that surface, type of bonding cement used, temperature of cement, curing time, pressure exerted on gage during curing, strain cycling of surface with mounted gage, temperature cycling of same, skill of the person who does the bonding, and other factors. A few general conclusions are presented based on refs. 13 and 14 . Apparently most bonded strain gages will show creep, which is attributed to the bonding cement used as well as to discontinuities in the wires at the end of loops and at the points of attachment of the lead wires. While creep usually shows up most after a static load had been applied for a period of time, some creep may result even from short time loading. One way of reducing this effect is by strain cycling the member to which the strain gage is mounted. This must be done judiciously because one of the other general characteristics of bonded strain gages appears to be their proneness to fatigue failure. On the basis of some 
tests performed at a strain of \pm 0.001 inch/inch, it appeared that some types of gages failed after about 16,000 cycles, while others were still good after 1,000,000 cycles. The conclusions drawn from these tests were as follows: Strain gages with a bakelite grid carrier have a longer life under dynamic conditions than paper backed gages. A number of the fatigue failures appeared at the junction between gage wires and lead wires. Gages with dual lead construction appear to have a longer life. Finally grid wire made of Iso-Elastic appear to last longer than those of copper-nickel alloys. Iso-Elastic, as mentioned previously, while possessing a higher gage factor than the copper-nickel alloy (constantan) has a larger temperature coefficient. In the matter of fatigue life, etched foil strain gages appear to hold some promise. The use of bonded strain gages at other than ambient room temperatures introduces other complications which will be discussed later on.

\section{FREQUENCY RESPONSE OF STRAIN GAGE ACCELEROMETERS}

In order for a general purpose accelerometer to measure applied accelerations faithfully over a wide frequency range, it should have a flat frequency response from steady state accelerations (D.C.) to the highest frequency component of the acceleration to be measured. In addition, the instrument should possess a phase shift characteristic linear with frequency? Such a phase shift characteristic, will result in a time delay of the recorded signals, but will cause no distortion by unequal relative shifts of different frequency components.

Most strain gage accelerometers are designed to be linear singledegree-of-freedom systems and experimental evidence indicates that their 
behavior generally approximates that of such systems.

The frequency response characteristic of a one degree-of-freedom seismic accelerometer with a damping ratio of 0.707 gradually decreases as the frequency increases, dropping 5\% below the steady state response when the frequency reaches 0.57 of the natural frequency. For this same damping ratio, the phase shift characteristic is linear within about \pm 2 ; from its steady state value of $0^{\circ}$ to $90^{\circ}$ at the natural frequency.

For a damping ratio of 0.59 , the frequency response characteristic first gradually rises with increasing frequency reaching a peak value 5\% above the steady state response at a frequency of 0.55 of the natural frequency. After that, the response drops, until it is 5\% below the steady state response at 0.87 of the natural frequency. The phase shift characteristic in this case is no longer linear, but deviates from linearity by as much as $6^{\circ}$.

For practical purposes this nonlinear phase response may be disregarded in comparison to the frequency response of the amplitude since this amplitude varies from the steady state response in all cases before the phase differs more than a few degrees from the linear.

The time lag between acceleration input to the instrument and its output is obtained from its phase characteristic. In the case of 0.707 of critical damping, the time lag is about 0.25 of the natural period of the instrument. A linear phase shift characteristic assures the correct reproduction of complex wave shapes of acceleration since all frequency components are shifted in phase proportionately, thus preserving the character of the wave shape.

There is no general criterion for the faithfulness of reproduction 
of a complex wave shape, since there is an infinite number of such possible shapes. Theoretical work at NBS 12 indicates that for input wave shapes which are either triangular or sinusoidal pulses, for an accuracy of reproduction of about $5 \%$ of the peak acceleration, the accelerometer should have a damping ratio of about 0.4 to 0.7 of critical, and a natural period of less than about one-third of the duration of the acceleration pulse. For a square pulse, it appears that a similar accuracy may be attained for a damping ratio of 0.7 and a natural period of less than one-third that of the input pulse.

It is apparent from the two cases given above that if the damping ratio in a given accelerometer changed from 0.707 to 0.59 , at a frequency of about 0.56 of the natural frequency, the instrument response would increase about 10\%. The change in response would be proportionately less at lower frequencies, for example, about $3 \%$ at 0.30 of the natural frequency. By restricting the frequency range of accelerations measured to a region far below the natural frequency of the instrument, the fidelity of the response can be made relatively independent of the damping ratio.

As mentioned earlier, there are cases where an instrument with a low natural frequency is used so as not to respond to extraneous high frequency accelerations. In such case, measurements would often be carried out close to the natural frequency of the instrument and the accuracy of these measurements would be highly dependent on the value of the damping ratio.

Commercial accelerometers generally employ a viscous liquid to supply the damping. For a one degree-of-freedom system with pure viscous damping supplied by a liquid of the silicone famlly, it can be shown 26 
that the damping ratio is directly proportional to the kinematic viscosity of the fluid over a wide range of viscosities. Thus, any change in viscosity of the damping fluid would affect the accuracy of dynamic measurements, particularly at frequencies approaching the natural frequency of the accelerometer. Changes in temperature of the damping fluid have a radical effect on its viscosity (this will be discussed more fully later on). For this reason specifying a damping ratio without specifying the fluid temperature at which it applies is rather meaningless.

Theoretically, in the case of pure viscous damping, the addition of damping fluid to an undamped single degree of freedom system should not affect the natural frequency of the system. Actually, however, some of the added fluid will be pushed back and forth by the movement of the seismic mass as it responds to accelerations. This will have the affect of increasing the seismic mass, thereby lowering the natural frequency of the instrument 17 For a manufacturer it is often much easier to determine the natural frequency of an accelerometer before it is filled with damping fluid. If the instrument is not rechecked after filling, considerable errors may result due to the inertia of the fluid if the originally determined value of natural frequency is used as the one applying to the damped instrument. In addition, some loss in sensitivity may result due to the buoyancy of the damping fluid which reduces the active unbalanced mass of the seismic element.

If in the design of a liquid damped accelerometer, the spacing between the moving mass and some element of the case is made very narrow to provide shear damping, certain complications may arise. Unless an 
additional large return path is provided for the moving fluid, its effective inertia will be increased as a function of the square of the velocity of the fluid in the narrow gap. If a high viscosity damping fluid (with an appreciable modulus of elasticity in shear) is used in this case, shear movement of the mass will also cause elastic deformation of the fluid in addition to viscous flow. This effectively adds another spring to the seismic system, resulting in a system response in the form of a fourth order differential equation (corresponding to a two degree-offreedom system)!l This may be the explanation for response curves obtained from some unbonded strain gage accelerometers which appeared to be those of two degree-of-freedom systems.

Although it is generally assumed that the fluid damping is linear, this is true only if no turbulence or bubbles exist. When very low viscosity damping fluids are used, turbulence may arise, manifesting itself as output nonlinearities in the high frequency and large amplitude regions of applied accelerations.

"Gas damping" which has recently come into use for strain gage accelerometers is discussed previously.

\section{PERFORMANCE CHARACTERISTICS}

\section{7-1. Accuracy and Fidelity.}

There are many properties which influence the quality of the measurements performed by an instrument, particularly a telemetering instrument. Among them are instmument characteristics like linearity, hysteresis, repeatability, temperature effects, acceleration and vibration effects, and others. In view of the many factors involved, it is meaning- 
less to give one figure of accuracy as an indication of the quality of the measurements possible without going into elaborate detail on all the conditions under which this figure applies. It is preferable to list as many of the instrument characteristics, as is possible and to let the user decide the overall accuracy of his measurements. This appears to be the present practice of many manufacturers of telemetering instruments with these measuring properties listed under a general heading entitled "Accuracy".

The properties listed above are "steady state characteristics" obtained from steady state calibrations with fairly well established methods with the aid of reliable working standards. Since most measurements in telemetering are made of time varying physical quantities, the dynamic characteristics of the instrument will have an important effect on the quality of the measurements. Such dynamic characteristics as frequency response, phase response, dynamic linearity, damping factor, distortion, variation of hysteresis with frequency, and others can neither be determined as readily and precisely as the "steady state characteristics", nor are the methods and working standards for their determination as well established or reliable. In view of these uncertainties it is desirable that the use of the term "accuracy" be confined to the description of the quality of steady state measurements. The term "fidelity" is suggested to describe the quality of dynamic measurements. The accuracy can be no better than the maximum error likely to be encountered in a carefur static calibration under stated environmental conditions and is usually expressed either as a percentage of the instrument range or in acceleration units. 


\section{7-2. Repeatability.}

Repeatability is the maximum difference between corresponding points of acceleration obtained by repeated uni-directional static calibrations and is expressed in acceleration units or as a percentage of the instrument range.

Actually, two types of repeatability exist: short term repeatability and long term repeatability, also called drift. "Short term" generally refers to a period of time of the order of minutes to a day over which the test is performed. "Long term" repeatability tests generally extend over from days to months.

7-2-1. Short Term Repeatability.

This may be a function of many factors, such as backlash, imperfect elasticity of elastic members, coldworking of elastic members, energy absorption of instrument from the quantity to be measured and minor variations in the local environment.

Tests to determine short term repeatability are performed with steady state input at other than zero, preferably near full scale. Short term variations of the output with zero input are seldom encountered and when they appear to occur are generally due to stray pickup or other faults of the output sensing equipment or possibly, in the case of strain gage pickup, a noisy excitation voltage supply. In tests, two bonded strain gage accelerometers ( $\pm 10 \mathrm{G}$ 's range) showed repeatability over a period of less than a day within $\pm 0.7 \%$ of range. Two unbonded strain gage accelerometers ( $\left.\pm 10 \mathrm{G}^{\prime} \mathrm{s}\right)$ showed repeatabilities within $\pm 0.4 \%$ and $\pm 0.8 \%$ of range over an eight hour period. Two others ( $\pm 50 \mathrm{G} ' s)$ tes- 
ted had repeatability of $0.28 \%$ of range over a few minutes, while another accelerometer with a range of $\pm 1.5 \mathrm{G}$ 's, had repeatability of $0.2 \%$ of range over a period of eight hours.

7-2-2. Long Term Repeatability.

Long term repeatability, sometimes referred to as drift, results from gradual changes in the property of materials, dimensions, and chemical changes, as well as from changes induced by varied environmental conditions and use.

To determine long term repeatability, repeated measurements are made of the instrument's output, with zero input as well as some value of input near full scale over a long period of time. From these data, values of long term repeatability may be given in terms of zero shift as well as sensitivity change (for linear pickup). Two 10 "G" bonded strain gage accelerometers were tested at $I G$ and long term repeatability was found to be within $0.35 \%$ and $1.4 \%$ of range over a period of four months. These same two 10 " $G$ " accelerometers repeated within $\pm 0.7,0.8 \%$ of the range at $\pm 1 G$ over periods between nine and eleven months.

In the case of the two $\pm 50 G$ unbonded strain gage accelerometers, zero shifts over a period of 2 months were about $1.2 \%$ of full scale and about $0.3 \%$ of full scale. During the same period of time, the sensitivity of the first instrument increased about $0.5 \%$, that of the second about $0.9 \%$. A 1.5G accelerometer showed a shift of $1.0 \%$ over a period of sixty days. Bonded and unbonded strain gage accelerometers appear to show repeatabilities of the same order of magnitude. 
7-3. Linearity (of the electrical output with respect to acceleration input.)

Linearity is described as the maximum excursion of any point from the best straight line of the plot of any careful static calibration performed under stated environmental conditions. The manner in which the best straight line is determined must be stated. Linearity is also expressed either in acceleration units or in percent of the range.

The linearity of both types of strain gage accelerometers should be quite good, since deflections involved are small and if properly designed, strain gages operate well within the elastic limit.

Experimentally, it is not easy to determine linearity precisely. Limitations are imposed by the experimental accuracy of the calibration and the repeatability of the instrument under test. The value of linearity assigned to the instrument cannot be any better than the repeatability. The scatter of experimental data will limit the determination of linearity, so that frequently, the conclusion drawn is that linearity is no worse than the scatter. Test results showed values of linearity (expressed as maximum deviations from mathematically determined straight line through all calibration points) to range from $0.6 \%$ to $1.0 \%$ of the range for bonded, and from $0.3 \%$ to $1.4 \%$ of the range for unbonded strain gage accelerometers.

7-4. Hysteresis.

Hysteresis may be defined as the summation of all effects, other than backlash, wherein the output assumes different values for the same value of input when that input is applied in an increasing or decreasing direction.

As in the case of linearity, as long as the instrument operates 32 
well within the elastic limits of springs and strain gages, the hysteresis should be quite small. As above, the short term repeatability of the instrument under test as well as the accuracy of the calibration will limit the precise determination of hysteresis. Manufacturers literature frequently combines hysteresis and linearity by stating "nonlinearity and hysteresis not more than -\% of full scale". Experimental results show that hysteresis values are of the order of $0.3 \%$ to $0.4 \%$ of the range for bonded accelerometers and $1.0 \%$ to $3.1 \%$ of the range for unbonded strain gage accelerometers.

7-5. Resolution.

The output of a strain gage, whether bonded or unbonded is a smooth function of applied strain. For this reason the resolution of a strain gage accelerometer, the ability to detect small changes in input level, will generally be that imposed by the associated equipment. 7-6. Response to Transverse Excitation.

The transverse response of an accelerometer represents the output when acceleration is applied to the instrument in a direction perpendicular to the sensitive axis of the instrument. Generally, the (steady state) transverse response (also called "cross coupling" or "cross talk") is expressed as the ratio of the sensitivity of the instrument to accelerations perpendicular to the sensitive axis to the sensitivity to accelerations along the sensitive axis.

7-6-1. Transverse Response to Steady State Accelerations.

Much of this transverse response is due to manufacturing tolerances and misalignments during assembly, which cause the true sensitive axis of the instrument to be not quite perpendicular or parallel (depending 
on design) to the mounting surfaces or other fiducial line. However, even if the instrument is mounted so that the sensitive axis is exactly perpendicular or paralled to the mounting, a minimum amount of cross talk will be present, referred to as "inherent" cross talk. Cross talk is also a function of the position of the mass of the spring mass system. In general, the effect of transverse accelerations on the output of the instrument is apparently greater when there is also full scale acceleration applied along the sensitive axis than when no acceleration is applied along the sensitive axis.

Referring to section 5, which discussed some design principles of bonded strain gage accelerometers, the deflection of the end of the single cantilever beam due to gravity is given by $u=\frac{w^{3}}{3 I Y} \cdot$ Thus, the deflection due to "G" units of accelerations will be uG. If in addition a transverse acceleration of $B$ " $G$ " units of acceleration acts along the beam or the weight $W$, at the end of the beam, it will produce a moment at the root of the beam of $B W(U G)$. The moment produced by acceleration acting along the sensitive direction will equal GWL, where $\mathrm{I}$ is the length of the beam. Within elastic limits, strain, and consequently strain gage output, are proportional to the bending moment at the section where the gages are attached. Therefore, the ratio of output due to acceleration along the sensitive direction will be equal to the ratio of the respective bending moments $\frac{B W u G}{G W L}=B \frac{U}{L}$. By using a configuration consisting of two cantilever beams in a Z-shaped arrangement connected to a common seismic mass, output due to transverse accelerations along the long dimension of the beam can be cancelled out almost completely. Tests on two bonded strain gage accelerometers show responses to 
transverse excitation ranging from $0.4 \%$ to $1.7 \%$.

Experimental values obtained for a low range $( \pm 1.5 \mathrm{G})$ accelerometer of the unbonded strain gage type show the transverse response to be less than the estimated experimental limits of error which range from about $1.2 \%$ to $1.8 \%$ of transverse acceleration. For a similar $\pm 50 G$ accelerometer, the transverse response was $0.3 \%$ of the acceleration. A gas damped unbonded strain gage accelerometer ( $\pm 10 \mathrm{G} ' s$ ) had a transverse response of $0.9 \%$.

Since transverse response appears to be greater when accelerations are also applied along the sensitive axis, tests are often performed by applying steady state acceleration at some known angle to the sensitive axis. This results then in two components of the accelerations; one along the sensitive axis and the other transverse to it. Unless, however, the location of the center of mass of the seismic system is known accurately, the components of acceleration cannot be accurately determined. Some of the above data may be inaccurate for this reason.

A promising way of determining the steady state transverse response appears to be one which the manufacturer can perform before the instrument is assembled. A known force (such as a spring) pulling the seismic mass transversely, while weights hanging from the mass simulate acceleration along the sensitive direction, would allow determination of the transverse response quite accurately。

7-6-2. Transverse Response to Vibrational Accelerations.

These strain gage accelerometers will generally also show a transverse response to vibrational accelerations, (sinusoidal or transient) as well as to steady state, accelerations. The effect of poor assembly 
methods during instrument construction may be magnified by resonance. An unbonded strain gage accelerometer with a natural frequency of $43 \mathrm{cps}$ showed maximum sinusoidal vibrational transverse response of $3.4 \%$ at 20 cps (for one transverse direction) and of $3.6 \%$ at $89 \mathrm{cps}$ in another one at right angles to the first one. Another unbonded strain gage accelerometer showed a transverse response of about $5 \%$ over a frequency range from 20 to $200 \mathrm{cps}$ for sinusoidal vibrations. The transverse response for a third one did not exceed $2 \%$ over a frequency range from 25 to 125 cps.

Laboratory measurements of the response to transverse vibrational accelerations on the assembled instrument can be quite good, since only the direction of the sensitive axis need be known.

7-7. Temperature Effects.

7-7-1. Slowly Changing Ambient Temperatures.

Slow changes in the ambient temperature may effect the operation of strain gage accelerometers in three ways by giving rise to zero shifts, changes in sensitivity and, by changing the viscosity of the damping fluid, thereby changing the damping ratio and consequently the dynamic response of the instrument. This is true for bonded as well as unbonded strain gage accelerometers. 7-7-1-1. Zero Shift.

Zero shift may be due to unsymmetrical changes in dimensions with temperature causing strain in the strain wires or it may be caused by temperature gradients causing unbalanced resistance changes in the strain gage bridge. The amount as well as the direction of zero shift due to slowly changing ambient temperatures are not readily predictable for any 
instrument but seem generally reproducible for any particular instrument and may be determined by test. It is, therefore, feasible in most cases to reduce this zero shift by a process of temperature compensation. This takes the form of a small resistor, which when added to one arm of the bridge, will undergo a change in resistance with temperature which will oppose the zero shift. While complete compensation appears impossible, in the case of unbonded strain gage accelerometers zero shifts normally ranging from about $0.02 \%$ to $0.05 \%$ of full scale per degree Fahrenheit, may be reduced to $0.01 \%$ of full scale per degree $F$ (for a temperature range from $-20^{\circ} \mathrm{F}$ to $+200^{\circ} \mathrm{F}$ ). Such compensation will not be effective for rapidly changing temperatures (thermal transients). It may, in fact, result in an even larger zero shift. Zero shifts occurring in bonded strain gage accelerometers have not been determined. One would expect them to be slightly larger than those of unbonded instruments due to the larger physical size with consequently larger possible changes in dimensions with temperature and greater possibilities for temperature gradients.

\section{7-7-1-2. Sensitivity Change.}

A change in sensitivity is primarily due to the temperature coefficient of the modulus of elasticity of the spring materials of the instmument's seismic system. For unbonded strain gage accelerometers, the sensitivity of the instrument may be expected to increase with increasing ambient temperature at the rate of from about $0.02 \% \mathrm{FS} /{ }^{\circ} \mathrm{F}$ to $0.03 \%$ FS $/^{\circ} \mathrm{F}$. The larger value applies where the strain wires supply most of the elastic restraint of the system. This agrees with the value of temperature coefficient of the modulus of elasticity for "constantan" wire 
of about $-0.00033 /{ }^{\circ} \mathrm{F}$. As in the case of zero shift, it is possible to reduce the changes in sensitivity of the unbonded instrument with temperature by a process of compensation. In this case, the compensating resistor is put in series with the entire bridge. Instruments, thus compensated, require a higher excitation voltage (generally about 15\% higher than non-compensated ones) to make up for the loss in the compensating resistor. Such a process of compensation will reduce the change in sensitivity to about $0.01 \%$ of full scale per degree Fahrenheit.

In the case of bonded strain gage accelerometers, changes of the modulus of elasticity with temperature of the cantilever beam on which the strain gages are mounted will determine the temperature variation of sensitivity. Alloys commonly used as the beam material like beryllium copper or phosphor bronze have temperature coefficients of the modulus of elasticity of about $-0.00020 /{ }^{\circ} \mathrm{F}$ and $-0.00021 /{ }^{\circ} \mathrm{F}$ respectively. This, then, would be expected to result in an increase of sensitivity with increasing temperature for a bonded strain gage accelerometer of about $0.02 \% \mathrm{FS} /{ }^{\circ} \mathrm{F}$. The result of a test on such an instrument showed a decrease in sensitivity of $2.3 \%$ FS for a decrease in temperature of about $103^{\circ} \mathrm{C}$. This is equivalent to a rate of change of sensitivity of about $0.012 \% \mathrm{FS} /{ }^{\circ} \mathrm{F}$.

While semiconductor strain gages are sensitive to temperature changes, these can be compensated. Test data are not available, but manufacturers literature claims zero shift and sensitivity change to be less than $1 \%$ per $100^{\circ} \mathrm{F}$ temperature change. 
7-7-1-3. Effects on Dynamic Characteristics.

Section 6 "Frequency Response of Strain Gage Accelerometers" shows how the value of the damping ratio will affect the frequency response characteristics of strain gage accelerometers and, thereby, the accuracy of dynamic measurements performed with these accelerometers. The most commonly used damping fluids are silicones. While their temperature coefficients of viscosity are considerably smaller than that of most other damping fluids they are still quite appreciable. A typical fluid (100 centistokes nominal viscosity) will show a variation in kinematic viscosity at $77^{\circ} \mathrm{F}$ (room temperature) of approximately $1.1 \% /{ }^{\circ} \mathrm{F}$. As pointed out in section 6, the damping ratio is directly proportional to the kinematic viscosity, consequently for this particular damping fluid, the damping ratio of the instrument using it would also be expected to vary $1.1 \% /{ }^{\circ} \mathrm{F}$. It can be seen that for the above fluid an increase in ambient temperature of about $18^{\circ} \mathrm{F}$ would change the damping ratio from 0.707 to0.59 with attendant possible increase of instrument response of 10\% (at 0.56 of the natural frequency).

Also, the damping may be affected by temperature induced changes in the dimensions of the passages in the instrument through which the damping fluid must pass. Such dimensional changes may be used in some cases to compensate for the change of viscosity of the damping fluid. If an increase in temperature, which results in a decrease in damping fluid viscosity, would also decrease the size of the passages, the damping ratio would not change as much. A practical way of reducing error due to viscosity variations with temperature as well as other tempera- 
ture errors is by the temperature control of the entire instrument. This is done by putting an electrical heater jacket around the instrument with a thermostat controlling the heating current mounted inside the accelerometer preferably in close contact with the damping fluid. The control temperature is usually in the range of $110^{\circ} \mathrm{F}$ to $135^{\circ} \mathrm{F}$, permitting temperature control of the instrument to be effective up to these temperatures (within limits of the thermostat) and down to temperatures as low as $0^{\circ} \mathrm{F}$ to $-65^{\circ} \mathrm{F}$. The low temperature limit depends on an available heater power, instrument size, insulation, and whether air surrounding instrument is moving or still. A bonded accelerometer had its heater on continuously when in moving air at $50^{\circ} \mathrm{F}$, or, in still air at $-20^{\circ} \mathrm{F}$.

Tests for two such instruments showed temperature control to be effective from $-65^{\circ} \mathrm{F}$ to $+119^{\circ} \mathrm{F}$ and $-65^{\circ} \mathrm{F}$ to $+113^{\circ} \mathrm{F}$. The range of temperature control for another unbonded strain gage accelerometer was found to be from $-45^{\circ} \mathrm{F}$ to $+136^{\circ} \mathrm{F}$. Tests on an unbonded strain gage accelerometer with gas damping showed the frequency response to be down $7 \%$ (at the equivalent of 0.5 of the natural frequency) for a temperature rise above ambient of about $120^{\circ} \mathrm{F}$. This instrument was not temperature controlled.

7-7-2. Thermal Transients.

The location of an instrument in close proximity to a rocket engine or to the skin of a high speed missile may result in the instrument's exposure to thermal transients. The effect of such transients would probably manifest itself in a zero shift, which would be a function of the magnitude and duration of the transient. Temperature compensated 
instruments may be even more effected than uncompensated ones due to the gradients between the pickoff and its compensating element.

A gas damped unbonded strain gage accelerometer showed a transient zero shift of about $5 \%$ of the range when subjected to a step function heat flux of $138 \mathrm{cal} / \mathrm{minute}$ through the base of the instrument. 7-8. Tolerance to Environmental Extremes.

While all environmental changes affect the measuring accuracy of strain gage accelerometers to some extent, if the environmental changes are severe enough, the instrument may be temporarily or even permanently disabled.

\section{7-8-1. Steady Acceleration Overload.}

If a steady state acceleration with an amplitude much larger than the full scale range of the instrument acts along the sensitive axis of a strain gage accelerometer, it may be damaged due to over-ranging, that is, by exceeding the elastic limit of strain gage wires, springs, or beam material (in the case of bonded strain gage accelerometers), permanent set may be introduced. In extreme cases, strain gage wires may actually break and thereby ruin the instrument.

To prevent this, the manufacturer generally builds stops into the instrument which prevent the seismic mass from travelling more than some nominal percentage beyond full scale range. Instruments using the "zero length strain gage" are immune to strain wire breakage, since the strain in the wires remains relatively constant with the displacement of the mass.

The limit stops are placed (frequently unsymmetrically) so as to 
Iimit displacement of the seismic mass corresponding to acceleration values ranging from about $110 \%$ to $190 \%$ of the range, with the majority near $120 \%$.

7-8-2. Vibration and Shock Along the Sensitive Axis.

The use of limit stops does not preclude damage due to overloads. Iarge vibrational accelerations within the operating frequency range of the accelerometer may cause the seismic mass to pound the stops very hard and damage the instrument. The same may be true of large amplitude shock accelerations.

Tests on a bonded strain gage accelerometer $( \pm 5 G)$ (stop at $+8 G$ and -9G) revealed a changed calibration and open circuited thermostat after the instrument had been subjected to a vibrational overload of +9G at $15 \mathrm{cps}$.

An unbonded strain gage accelerometer $( \pm 1.5 \mathrm{G})$ showed no apparent damage due to a vibrational overload of $\pm 14 \mathrm{G}$ at $35 \mathrm{cps}$. It is extremely difficult to determine the effect of the environmental extremes experienced by a telemetering instmment in flight on the accuracy of the data obtained by means of this instrument. This is not only due to difficulties in simulating such environmental extremes in the laboratory, but also due to the fact that it is hard to predict and determine their magnitudes during flight tests. In addition, while the failure of an instrument due to enviromental extremes is quite clear cut, "damage" or "unsatisfactory operation" allows a wide latitude of interpretations. Another difficulty exists in the fact that many cases of failure or "damage" are due to imperfections of materials, poor assembly, improper inspection, and other factors pertaining to a particular instmment and 
not necessarily to all instruments of the same type or class. Thus, failure of one instrument does not automatically imply failure of others of the same type under similar circumstances.

7-8-3. Acoustic (Airborne) Noise.

With the advent of high power jet engines and rocket engines, high acoustic sound levels generated by them created another environmental problem. These high level sound pressures may excite to resonance structural members on which instruments are mounted thereby producing vibration effects in the instmments. The remarks above on vibration effects would apply then. A more direct effect has been reported for the case of an unbonded strain gage accelerometer. This instrument when exposed to an acoustic field of about $165 \mathrm{DB}$ intensity at 600 cps showed outputs of the order of $10 \%$ to $30 \%$ of full scale. This was apparently due to resonant excitation of the instruments' top cover plate and transmission of this vibration to the mass through the damping fluid. 7-8-4. Extremes of Ambient Temperatures. 7-8-4-1. Effects on Unbonded Strain Gages.

In the case of conventional unbonded strain gage accelerometers, one of the factors establishing the operating temperature range is the maximum allowable strain in the wire.

Assuming a typical design with a one inch gage length of "Advance" wire, a brass frame, and a full scale range of strain of \pm 0.0015 inches/ inch, a temperature range from $-40^{\circ} \mathrm{F}$ to $+200^{\circ} \mathrm{F}$ will set up strains of \pm 0.0003 inches/inch. Since the strain wires must be mounted under enough initial tension to allow for both of the above values of strain, a maxi- 
mum strain of 0.0036 inches/inch may exist at full scale range and $+200^{\circ} \mathrm{F}$. This value of strain is close to that which caused permanent set in some experiments on strain wire characteristics. Again, "zero length" strain gages are not subject to this.

Another factor is the change in characteristics of "Advance" with time at high temperatures $\left(500^{\circ} \mathrm{F}\right)$. Oxidation and corrosion apparently take place and gradually change the electrical and mechanical properties of the strain wire. $500^{\circ} \mathrm{F}$ appears to be the present upper limit for reliable performance of unbonded strain gages.

7-8-4-2. Effects on Bonded Strain Gages.

Manufacturers recommendations for bonded strain gages indicate that "Advance" (constantan) gages with paper backs may be used at temperatures up to $180^{\circ} \mathrm{F}$, those with Bakelite backs may be used up to about $300^{\circ} \mathrm{F}$ without damage. Tests performed at $\mathrm{NBS}^{2}$ on temperature characteristics of bonded strain gages indicate that paper backed gages are not reliable above about $100^{\circ} \mathrm{F}$, bakelite or epoxy resin backed gages are good up to about $200^{\circ} \mathrm{F}$. Creep may be present at temperatures as low as $100^{\circ} \mathrm{F}$ if a strain level exists for any length of time. It appears to increase with temperature. Some of the creep originates in the bonding cement. Local strains at the end of the wire loops and at junctions between gage wires and lead wires will also contribute to the creep.

Strain gages have been tested at temperatures as low as $-310^{\circ} \mathrm{F}$, and appeared to perform satisfactorily. The gage factor for "Advance" gages seems to decrease in the order of one percent between room temperature and about $-200^{\circ} \mathrm{F}$. Other tests indicate that the gage factors of some "Advance" gages decrease in the order of $3 \%$ between room tempera- 
ture and about $+250^{\circ} \mathrm{F}$. Reports on test results show a wide variety of results and the above values only indicate a general trend. The properties of bonded strain gages appear to vary not only among specimens of the same type, but depend on mounting procedures, type of current used, temperature and humidity prevailing at the time of mounting, curing temperature and curing time for bonding cement, etc.

It has been definitely established that strain cycling and temperature cycling of the gages after mounting is beneficial in reducing creep and zero shifts and generally stabilize the characteristics of the gages. High temperature strain gages (for temperatures beyond $250^{\circ} \mathrm{F}$ ) are available and have been tested. Again, a rather wide range of results was obtained. Apparently high temperature gages made of "Advance" wire or foil are satisfactory up to about $500^{\circ} \mathrm{F}$ with a gage factor somewhat higher than at room temperature. Some "Advance" gages show resistance changes with time and temperature independent of strain. Other materials have been used for high temperature gages; gages made with Nichrome V wire or foil seem satisfactory up to about $600^{\circ} \mathrm{F}$ with a gage factor lower than at room temperature. Another material, Karma, may be suitable for even higher temperatures (up to $1000^{\circ} \mathrm{F}$ ) although some tests have indicated temperature hysteresis. Commercial high temperature gages claim operating ranges up to $1800^{\circ} \mathrm{F}$, although presumably zero drift would make steady state measurements unreliable.

One type of ceramic bonding cement, recommended for high temperature gages, appears rather soft and might easily be eroded by the action of damping fluid in motion.

Semiconductor strain gages are advertised as being suitable for 
operation at temperatures from $-320^{\circ} \mathrm{F}$ to $+650^{\circ} \mathrm{F}$.

\section{7-8-4-3. Effects on Cantilever Beam (Spring) Materials.}

In addition to changes of the modulus of elasticity with temperature, other effects occur at elevated temperatures. These are plastic readjustments as a result of stress at time and temperature: "relaxation", which refers to constant strain, and "creep", which refers to constant stress. Practically speaking, both have the same effect on measurements with cantilever beam type strain gage accelerometers: they cause zero shift and may cause eventual operation of the beam in a nonlinear stressstrain region. For alloys like beryllium copper or phosphor bronze, these effects are apparently very small at ambient temperatures up to near $400^{\circ} \mathrm{F}$. 7-8-4-4. Damping.

Large changes in temperature will change the viscosity of the damping fluid radically, and thereby change the dynamic characteristics of a fluid damped instrument. As an example, a silicone damping fluid with a viscosity of 100 centistokes at $+77^{\circ} \mathrm{F}$, will have a viscosity of 490 at $-30^{\circ} \mathrm{F}$, and 32 at $+200^{\circ} \mathrm{F}$. If an accelerometer, filled with this damping fluid, has a damping ratio of 0.707 at $77^{\circ} \mathrm{F}$, the corresponding damping ratios at $-30^{\circ} \mathrm{F}$ and $+200^{\circ} \mathrm{F}$ will be about 3.5 and 0.23 . The significance of this on the frequency response can be seen by considering the response of the accelerometer to a sinusoidal acceleration at frequency of 0.57 of the natural frequency where at $77^{\circ} \mathrm{F}$, and damping ratio of 0.707 , the frequency will be down $5 \%$ from the steady state value. At $+200^{\circ} \mathrm{F}$, the response will be $38 \%$ above the steady state response. At $-30^{\circ} \mathrm{F}$, damping 
ratio 3.5, the response will have dropped to about $25 \%$ of the steady state response. Some of the silicones solidify between $-40^{\circ} \mathrm{F}$ and $-70^{\circ} \mathrm{F}$ and, thereby, prevent functioning of the instmment. (It appears, then, that temperature control is imperative for acceleration measurements at low ambient temperature with fluid damped accelerometers.)

At high ambient temperatures, the damping fluid imposes other limitations. While the flash point for a DC 200 fluid of 100 centistokes is near $600^{\circ} \mathrm{F}$, for a 5 centistokes fluid it is about $275^{\circ} \mathrm{F}$. If these fluids are kept at high temperatures for a period of time, some of the fluid is lost through evaporation, the viscosity of the remainder will have changed somewhat. Thus the shelf life of the instrument would be limited by the storage temperature. Based on the characteristics of the damping fluids above, an upper limit of ambient temperature of about $300^{\circ} \mathrm{F}$ would seem a reasonable one for future design. A typical silicone damping fluid with a viscosity of 100 centistokes will show a change in volume of $8 \%$ over a temperature range from $0^{\circ} \mathrm{F}$ to $+200^{\circ} \mathrm{F}$. Most manufacturers provide an elastic expansion chamber in the instrument to prevent leakage or the formation of air bubbles in the fluid when the ambient temperature changes. Gas damping varies much less with temperature as shown in section 4-4-3, and shows promise for high temperature operation. 7-8-5. Ambient Pressure Variations.

While ambient pressure variations have no effect as such on the operation of strain gage accelerometers. It has been found that some of these instruments (supposedly "pressure tight") have leaked damping fluid under comparatively mild pressure variations. The loss of damping fluid 
may cause air bubbles in the fluid and consequent spurious dynamic responses.

\section{7-8-6. Effects of Nuclear Radiation.}

The physical properties of many materials are altered in the presence of high energy radiation?, 15 The changes vary with the type, density and duration of the radiation, and the type and structure of the material. Organic compounds appear to be affected harmfully by beta, gamma, and neutron radiation. Metals seem to be affected chiefly by neutrons.

Organic insulators will break down after prolonged exposure and also lose structural strength. Inorganic insulators can be used instead. For bonded strain gages, the susceptibility of the cements poses the most serious problem at present.

Irradiation appears to increase the hardness and tensile strength of metals and decrease their ductility. In addition, metals exhibit an increase in electrical resistance.

Absorption of nuclear radiation by a strain gage will increase its internal temperature, thereby affecting its gage factor and linearity.

Semiconductor strain gages will undergo severe permanent changes in electrical characteristics.

Finally, there may be hazards to personnel due to the radioactivity induced in the materials of the instruments. This radioactivity will persist for a period of time depending on the characteristics of the radiation and the materials.

7-8-7. Other Environmental Conditions.

Humidity, salt spray, fungus, sunshine, rain, sand and dust would not be expected to have any appreciable effect on the instruments. Some 
of these effects may decrease the leakage resistance between the electrical terminals on the outside of the accelerometer, but since the instruments are essentially low resistance devices, the effect of the changed leakage resistance should be negligible. 
TABLE I

CHARACTERISTICS OF SOME COMMERCIAI UNBONDED STRAIN GAGE ACCELEROMETERS

\begin{tabular}{|c|c|c|c|c|c|c|}
\hline TYPE & $\begin{array}{c}\text { RANGE } \\
\pm G \text {-UNIITS }\end{array}$ & $\pm \mathrm{mv}^{\mathrm{Q}} \mathrm{volt}$ & $\begin{array}{r}f_{n} \\
c p s\end{array}$ & $\begin{array}{c}E \\
\text { VOLTS }\end{array}$ & $\begin{array}{c}\text { BRIDGE } \\
\text { RESISTANCE } \\
\text { OHMS }\end{array}$ & $M=\frac{f_{n}^{2}}{G}$ \\
\hline$S-I$ & \pm 0.5 & 2.00 & 21 & 11 & 350 & 882 \\
\hline S-2 & \pm 2.0 & 3.89 & 100 & 9 & 350 & 5000 \\
\hline$s-3$ & \pm 5.0 & 4.55 & 190 & 11 & 350 & 7220 \\
\hline$s-4$ & \pm 200 & 4.00 & 850 & 11 & 350 & 3610 \\
\hline$s-5$ & \pm 50 & 4.58 & 550 & 12 & 350 & 6050 \\
\hline$s-6$ & \pm 10 & 4.00 & 350 & 8 & 300 & 12250 \\
\hline$s-7$ & \pm 0.5 & 2.22 & 5 & 9 & 350 & 50 \\
\hline S-8 & \pm 20 & 2.08 & 12 & 12 & 350 & 7.2 \\
\hline S-9 & \pm 50 & 4.00 & $360 *$ & 5 & 350 & $2500 *$ \\
\hline$S-10$ & \pm 25 & 4.00 & $790 *$ & 5 & 350 & $24700^{*}$ \\
\hline C-II & \pm 5 & 4.00 & 300 & 5 & 350 & 18000 \\
\hline$C-12$ & \pm 500 & 4.00 & 2900 & 5 & 350 & 16800 \\
\hline
\end{tabular}

* Computed. These are gas damped accelerometers. 
TABI,E 2

A. CHARACTERISTICS OF SOME COMMERCIAL BONDED STRAIN GAGE ACCELEROMETERS

\begin{tabular}{llccccr}
\hline TYPE & $\begin{array}{c}\text { RANGE } \\
\pm \text { G-UNITS }\end{array}$ & $\begin{array}{c}\text { Q } \\
\pm m v / \text { volt }\end{array}$ & $\begin{array}{c}f_{n} \\
\mathrm{cps}\end{array}$ & $\begin{array}{c}\mathrm{E} \\
\text { VOLTS }\end{array}$ & $\begin{array}{c}\text { BRIDGE } \\
\text { RESISTANCE } \\
\text { OHMS }\end{array}$ & $\mathrm{M}=\frac{f_{n}{ }^{2}}{G}$ \\
\hline T-I & \pm 2 & 2.5 & 25 & 15 & 300 & 313 \\
T-2 & \pm 30 & 2.5 & 110 & 15 & 300 & 404 \\
B-3 & \pm 3 & 4.0 & 8 & 8 & 120 & 21 \\
B-4 & \pm 100 & 4.7 & 75 & 8 & 120 & 56 \\
B-5 & \pm 100 & 3.1 & 185 & 8 & 120 & 342
\end{tabular}

B. CHARACTERISTICS OF SOME COMMERCIAL ACCELEROMETERS

WITH SEMICONDUCTOR STRAIN GAGES

\begin{tabular}{lllllll}
\hline$K-1$ & $\pm I$ & 50 & 110 & 20 & $400 *$ & 12100 \\
$K-2$ & \pm 20 & 50 & 500 & 20 & $400 *$ & 12500
\end{tabular}

* Output impedance 


\section{REFERENCES}

1. M. Heteny1. "Handbook of Experimental Stress Analys1s," John Wiley and Sons, Inc., New York, 1950.

2. "Characteristics and Applications of Resistance Strain Gages." National Bureau of Standards Circular No. 528, 1ssued 1954.

3. U. Yarnell. "Resistance Strain Gages," Electronic Engineering, London, 1951.

4. M. R. Behar. "The Handbook of Measurement and Control," Instruments Publishing Company, Inc., Pittsburgh, Pa., 1951.

5. "Statham Transducer Element" Bulletin 1.0, Statham Laboratories, Inc., Los Angeles, California, 1956.

6. "The Statham Zero-Length Unbonded Strain Gage" Bulletin 1.02, Statham Laboratories, Inc., Los Angeles, California, 1957.

7. "A Study of Force and Displacement Measuring Techniques", Part I "Linear and Angular Displacement Measurement Techniques", WADD, ARDC, Wright-Patterson Air Force Base, Ohio, 1960.

8. "Pressure Transducing and Instrumentation Techniques" Vol. I, Book 2 - Part B "Transmitting Techniques", WADD Technical Rept. No. 59743, WADD, ARDC, Wright-Patterson Air Force Base, Ohio, 1960.

9. D. E. Weiss. "Design and Application of Accelerometers," Proceedings of the Soeiety for Experimental Stress Analysis, Vol. IV, No. 2, 1947, pp. 89-99.

10. W. V. Basset. Discussion following reference 9, pp. 100-102. 
11. "Instrument Notes" Statham Laboratories, Inc., (Statham Instruments, Inc.), Los Angeles, California:

No. 2. "Response Characteristics of a Simple Instrument", 1950.

No. 5. "Temperature Compensation of Bridge Type Transducers", 1951.

No. 9. "Design Parameters for Linear Accelerometers, 1952.

No. 12. "The Meaning of "Natural Frequency", 1949.

No. 13. "The Mass Effect in Fluid Damping", 1950.

No. 23. "Secondary Effects in Seismic Systems", 1952.

No. 33. "Some Characteristics of Gas-Damped Accelerometers", 1958.

12. S. Levy and W. Kroll. "Response of Accelerometers to Transient Accelerations," Journal of Research of the National Bureau of Standards, Vol. 45, No. 4, October, 1950.

13. "Characteristics of Resistance Strain Gages". B. L. Bloss. Paper No. 90-NY60, Instrument Soclety of America, Sept., 1960.

14. "SR-4 Strain Gage Evaluation Report", Technical Data No. 4310-3, Baldwin-Lima-Hamilton, August, 1958.

15. "Materials for Instruments in Radiation Service", RP 25.1, Instrument Society of America, December, 1951.

16. "Shock and Vibration Handbook", McGraw-Hill Book Co., Inc., 1961. 
LIST OF SYMBOLS USED

A Peak acceleration amplitude, inches per second per second

B Transverse acceleration, "G" units

E Excitation voltage, volts

G Maximum range of instrument, "G" units

I Moment of inertia of beam, inches ${ }^{4}$

$\mathrm{K}_{\mathrm{S}} \quad$ Gage factor of strain wire

I Length of beam, inches

Q Sensitivity, millivolts out per volt of excitation

$\mathrm{R} \quad$ Resistance of each active arm of strain gage bridge, ohms

S Total length of wire in active arms of bridge, inches

V Electrical output, volts

W Weight at end of beam, pounds

Y Modulus of elasticity, pounds per square inch

Z Distance along beam from fixed end, inches

$\alpha \quad$ Acceleration due to gravity, inches per second per second

c Equivalent viscous damping constant, pounds per inch per second

$\mathrm{C}_{\mathrm{C}} \quad 2 \sqrt{\mathrm{km}}$, the critical damping constant, pounds per inch per second

d Diameter of strain wire, inches

$f_{n} \quad$ Natural frequency, cycles per second

h Height of beam, inches

$\mathrm{k} \quad$ Spring constant, pounds per inch

m Mass of seismic weight, pounds

$\mathrm{n} \quad \frac{\mathrm{C}}{\mathrm{C}_{\mathrm{C}}}$, the damping ratio 

$\mathrm{p} \quad \sqrt{\frac{\mathrm{k}}{\mathrm{m}}}$, natural circular frequency, radians per second
$u \quad$ Deflection of end of beam, inches
w Circular frequency of case displacement, radians per second
$\mathrm{x} \quad$ Relative displacement between seismic mass and case, inches
$x_{\text {peak }}$ Maximum displacement of seismic mass from its zero position, inches
y Displacement of case, inches
E Strain in Fibre, inches per inch
م Resistivity of strain wire, ohms per circular mil foot
$\boldsymbol{\sigma}$ Stress in fibre, pounds per square inch 


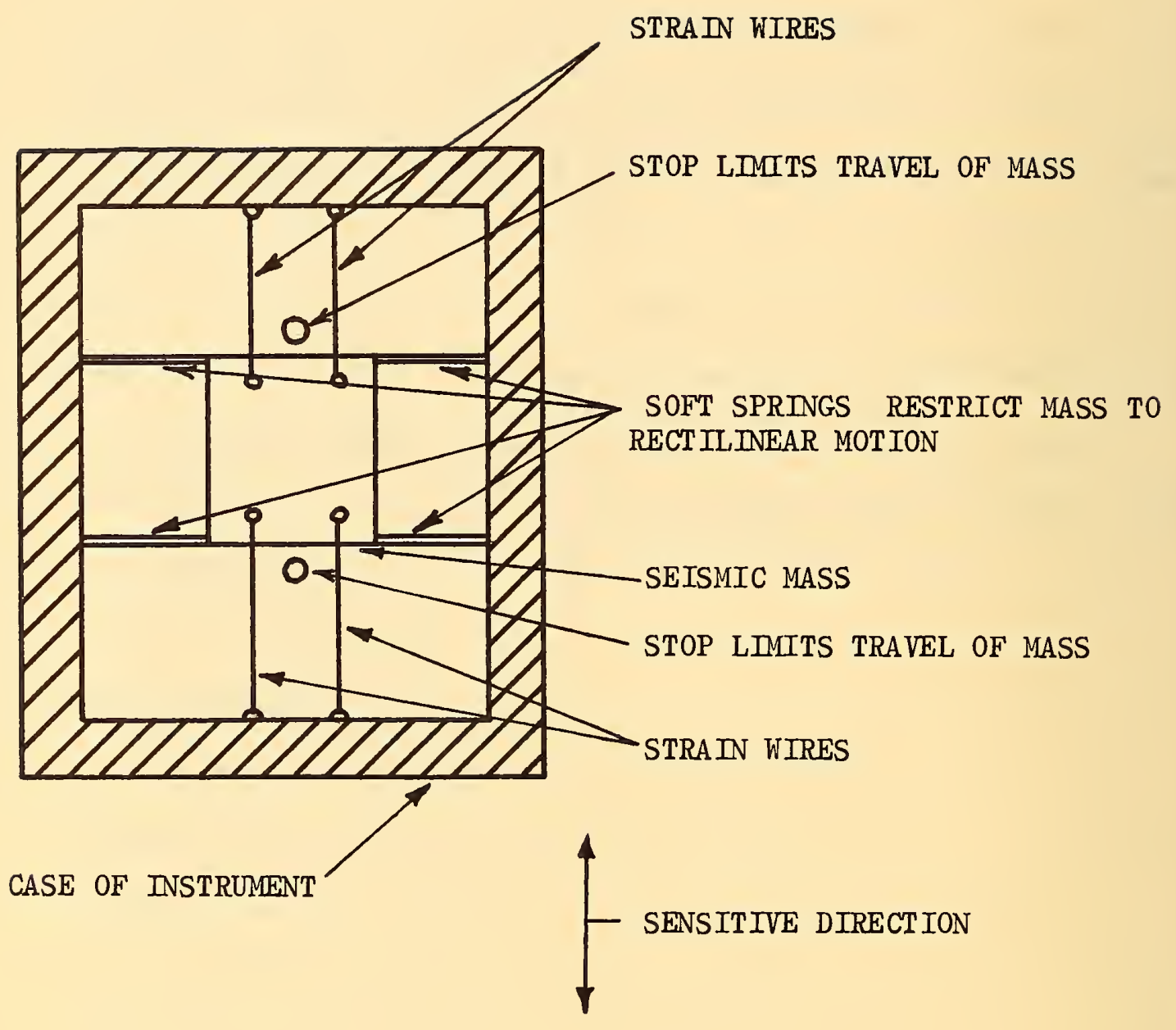

Figure 1 Principle of Unbonded Strain Gage Accelerometer 


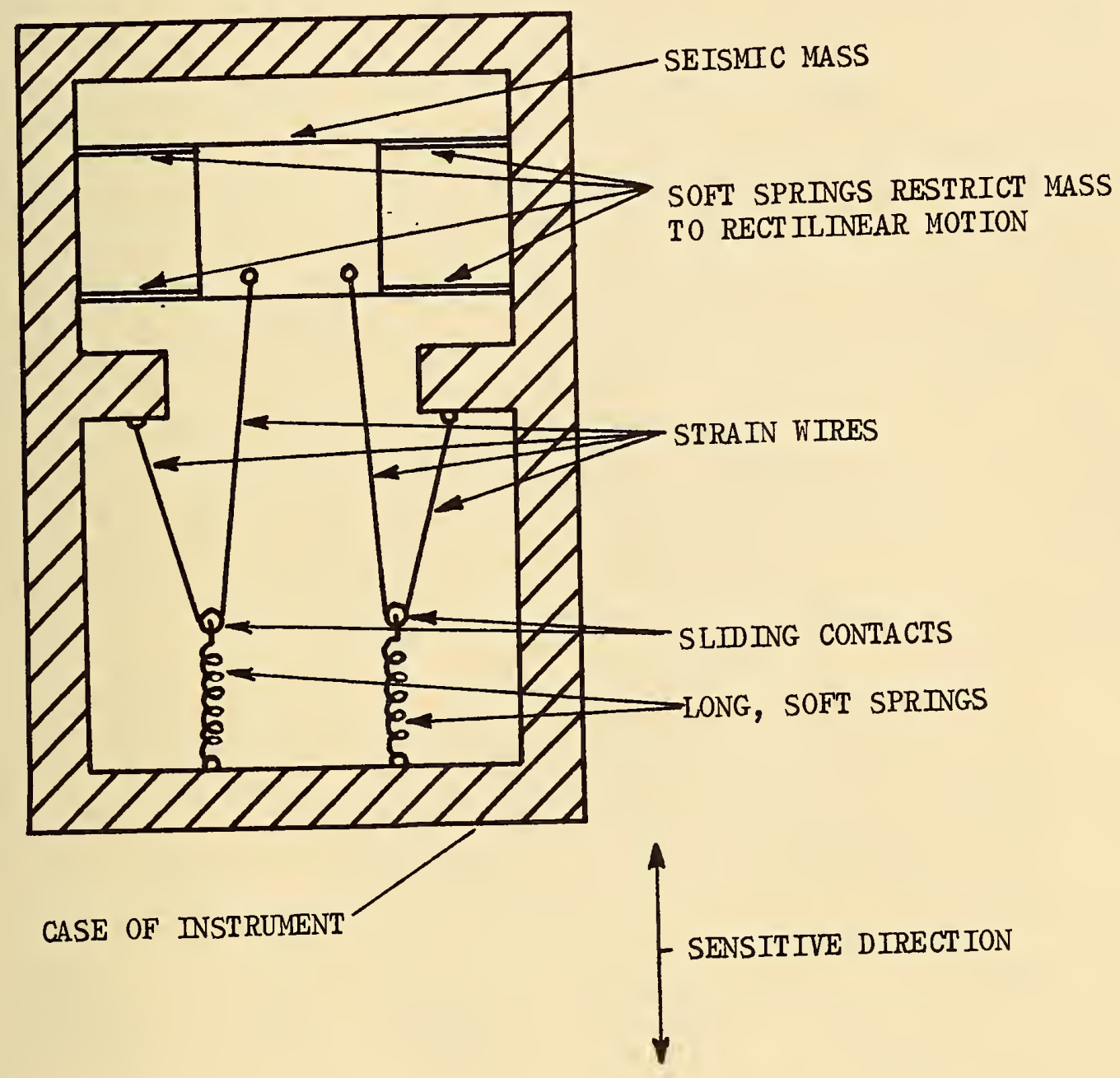

Figure 2 Principle of "Zero Length" Strain Gage Accelerometer 
NATIONAL BUREAU OF STANDARDS

A. V. Astin, Director

\section{THE NATIONAL BUREAU OF STANDARDS}

The scope of activities of the National Bureau of Standards at its major laboratories in Washington, D.C., and Boulder, Colorado, is suggested in the following listing of the divisions and sections engaged in technical work. In general, each section carries aut specialized research, development, and engineering in the field indicated by its title. A brief description of the activities, and of the resultant publications, appears on the inside of the front cover.

WASHINGTON, D.C.

Electricity. Resistance and Reactance. Electrochemistry. Electrical Instruments. Magnetic Measurements Dielectrics. High Voltage.

Metrology. Photometry and Colorimetry. Refractometry. Photographic Research. Length. Engineering Metrology. Mass and Scale. Volumetry and Densimetry.

Heat. Temperature Physics. Heat Measurements. Cryogenic Physics. Equation of State. Statistical Physics. Radiation Physics. X-ray. Radioactivity. Radiation Theory. High Energy Radiation. Radiological Equipment. Nucleonic Instrumentation. Neutron Physics.

Analytical and Inorganic Chemistry. Pure Substances. Spectrochemistry. Solution Chemistry. Standard Reference Materials. Applied Analytical Research. Crystal Chemistry.

Mechanics. Sound. Pressure and Vacuum. Fluid Mechanics. Engineering Mechanics. Rheology. Combustion Controls.

Polymers. Macromolecules: Synthesis and Structure. Polymer Chemistry. Polymer Physics. Polymer Characterization. Polymer Evaluation and Testing. Applied Polymer Standards and Researcḥ: Dental Research.

Metallurgy. Engineering Metallurgy. Microscopy and Diffraction. Metal Reactions. Metal Physics. Electrolysis and Metal Deposition.

Inorganic Solids. Engineering Ceramics. Glass. Solid State Chemistry. Crystal Growth. Physical Properties. Crystallography.

Building Research. Structural Engineering. Fire Research. Mechanical Systems. Organic Building Materials. Codes and Safety Standards. Heat Transfer. Inorganic Building Materials. Metallic Building Materials.

Applied Mathematics. Numerical Analysis. Computation. Statistical Engineering. Mathematical Physics. Operations Research.

Data Processing Systems. Components and Techniques. Computer Technology. Measurements Automation. Engineering Applications. Systems Analysis.

Atomic Physics. Spectroscopy. Infrared Spectroscopy. Solid State Physics. Electron Physics. Atomic Physics. Instrumentation. Engineering Electronics. Electron Devices. Electronic Instrumentation. Mechanical Instruments. Basic lnstrumentation.

Physical Chemistry. Thermochemistry. Surface Chemistry. Organic Chemistry. Molecular Spectroscopy. Molecular Kinetics. Mass Spectrometry.

Office of Weights and Measures.

BOULDER, COLO.

Cryogenic Engineering Laboratory. Cryogenic Equipment. Cryogenic Processes. Properties of Materials. Cryogenic Technical Services.

\section{CENTRAL RADIO PROPAGation LABORATORY}

Ionosphere Research and Propagation. Low Frequency and Very Low Frequency Research. Ionosphere Research. Prediction Services. Sun-Earth Relationships. Field Engineering. Radio Warning Services. Vertical Soundings Research.

Radio Propagation Engineering. Data Reduction Instrumentation. Radio Noise. Tropospheric Measurements. Tropospheric Analysis. Propagation-Terrain Effects. Radio-Meteorol ogy. Lower Atmosphere Physics.

Radio Systems. Applied Electromagnetic Theory. High Frequency and Very High Frequency Research. Modulalation Research. Antenna Research. Navigation Systems.

Upper Atmosphere and Space Physics. Upper Atmosphere and Plasma Physics. Ionosphere and Exosphere Scatter. Airglow and Aurora. Ionospheric Radio Astronomy.

\section{RADIO STANDARDS LABORATORY}

Radio Physics. Radio Broadcast Service. Radio and Microwave Materials. Atomic Frequency and Time-Interval Standards. Millimeter-Wave Research.

Circuit Standards. High Frequency Electrical Standards. Microwave Circuit Standards. Electronic Calibration Center. 


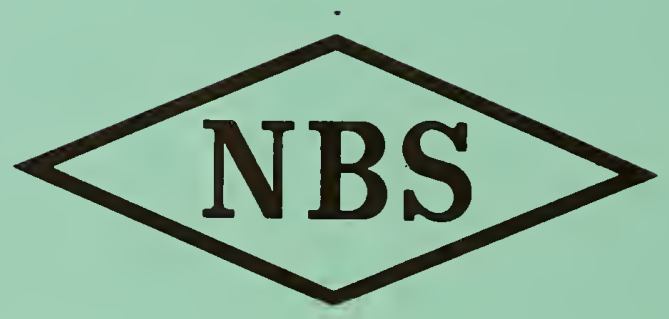

